\title{
Exserohilum rostratum causing sugarcane leaf spot in Iran
}

\author{
A. Ahmadpour • S. Karami • Z. Heidarian • M. Javan-Nikkhah
}

Received: 13 December 2012 / Accepted: 3 June 2013 /Published online: 4 July 2013

(C) Australasian Plant Pathology Society Inc. 2013

\begin{abstract}
A new sugarcane leaf spot disease caused by Exserohilum rostratum was found in Ahvaz, southwestern Iran during a series of surveys on fungal species causing sugarcane leaf diseases in 2011. Three single spore derived isolates were obtained from diseased sugarcane leaves and the pathogenicity of each isolate to sugarcane plants was confirmed by inoculation tests based on Koch's postulates. The isolates were identified as members of E. rostratum based on their morphological characters as well as rDNAITS (internal transcribed spacer) sequences. This is the first report of leaf blight caused by E. rostratum on S. officinarum in Iran.
\end{abstract}

Keywords Monocotyledonous plants · Pathogenicity · Pathogen identification · ITS

Sugarcane (Saccharum officinarum L.) is a tall growing monocotyledonous crop plant that is cultivated in the tropical and subtropical regions of the world primarily for its ability to store concentrations of sucrose, or sugar, in the internodes of the stem. This plant is cultivated in southern regions of Iran. Exserohilum rostratum causes leaf spot on grasses (Sivanesan 1987) and is opportunistic, etiologic agent of sinusitis, which may extend to the central nervous system, and keratitis, as well as cutaneous and subcutaneous mycosis in human (Revankar and Sutton 2010). The fungus causes disease symptoms on more than 30 plant species covering 28 genera in 11 families, including many economically important crops such as corn, rice, sugarcane, sweet sorghum and tomato (Zummo 1986; Leonard et al. 1988; Okoli and Erinle 1990; Cardona and González 2007).

\footnotetext{
A. Ahmadpour $(\bowtie) \cdot S$. Karami $\cdot$ Z. Heidarian $\cdot$ M. Javan-Nikkhah Department of Plant Protection, University College of Agriculture and Natural Resources, University of Tehran, Karaj, Iran e-mail: ahmadpour.abdollah@gmail.com
}

In the summer of 2011 in sugarcane farms of Ahvaz, in southwestern Iran, leaf spot symptoms were observed. Leaf spot symptoms were large and elongated with black to red margins and gray center (Fig. 1a). Leaves were sampled and surface-sterilised before being placed under near-UV light on $12 \mathrm{~h}$ diurnal cycle at room temperatures $23 \pm 2{ }^{\circ} \mathrm{C}$ to promote sporulation in the lesion. Single spores were then transferred to tap water agar with autoclaved wheat straw (TWA+wheat straw) plates for 10-14 days (Sivanesan 1987). Three isolates (Ex 1, Ex 2 and Ex 3) of Exserohilum sp. were isolated from lesions on symptomatic leaves. Measurement and microphotographs were taken from slide mounts in lactophenol using an Olympus light microscope (model BH2). Fungal colony was olivaceous brown on potato dextrose agar (PDA). Conidiophores were single, cylindrical, geniculate, dark brown, up to $200 \mu \mathrm{m}$ long, 5-7 $\mu \mathrm{m}$ thick, with a swollen basal cell (Fig. 2a). Conidia straight to slightly curved, ellipsoidal to narrowly obclavate or rostrate, brown, 6-16 distoseptate, basal septum darker and thicker than other septum, $15-200 \times 7-29 \mu \mathrm{m}$, with a distinctly protruding basal hilum (Fig. 2b, c). Germination of conidia is monopolar and bipolar. Based on morphological characteristics, the isolates were further identified as Exserohilum rostratum (Drechs.) Leonard \& Suggs (Sivanesan 1987). Dried culture vouchers have been deposited in the herbarium in the Department of Plant Protection, Faculty of Agricultural Sciences \& Engineering, University College of Agriculture and Natural Resources, University of Tehran, Karaj, Iran (TUPP).

Genomic DNA was extracted using the method of Liu et al. (2000). The one isolate (Ex 1) was subjected to PCR amplification of the internal transcribed spacer ITS1-5.8S-ITS2 regions with universal primer pair ITS1/ITS4 (White et al. 1990). The reaction mixture and PCR conditions were the same as described by Ahmadpour et al. (2012). The sequence was deposited into GenBank (KC198082). The ITS sequence comparison showed $99 \%$ identity to E. rostratum type strain 
Fig. 1 Symptoms of leaf spot caused by Exseyrohilum rostratum on sugarcane. a leaf spot symptoms on naturally infected sugarcane in field. $\mathbf{b}$ leaf spot symptoms on infected sugarcane under greenhouse conditions 3-4 days after inoculation
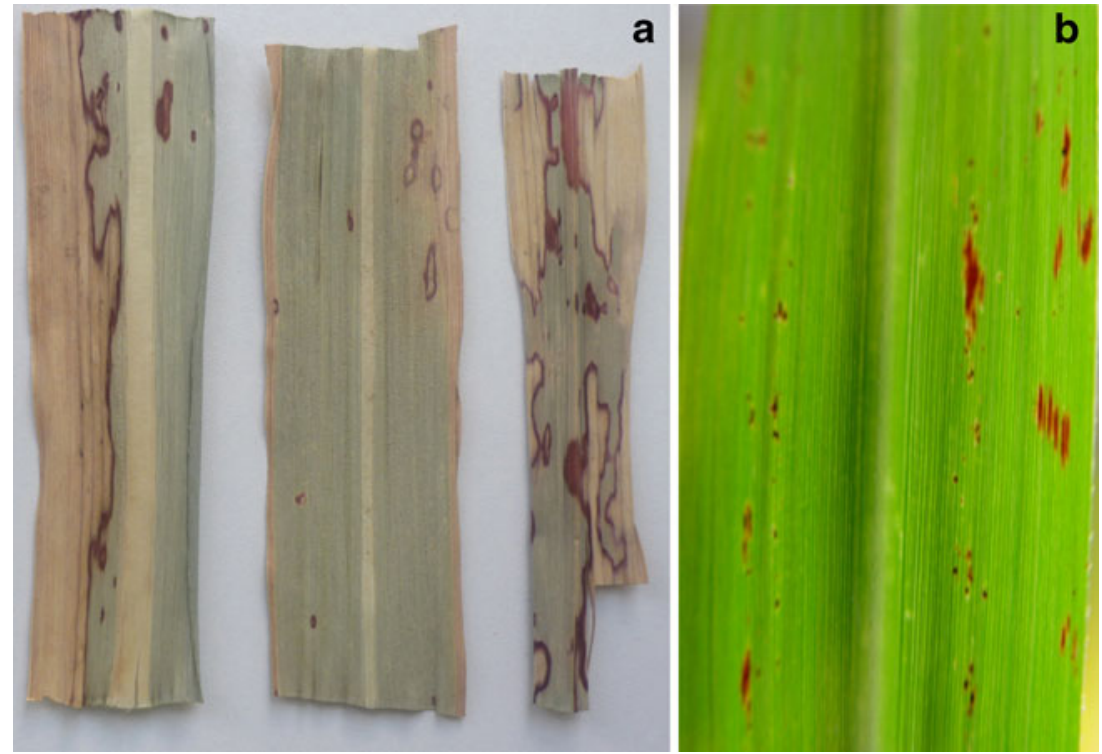

CBS 467.75 (GenBank accession HE664034). According to morphological and molecular analysis, the isolates were identified as E. rostratum.

Pathogenicity tests were conducted on 2-month-old sugarcane plants by spraying a conidial suspension of the fungus $\left(10^{5}\right.$ conidia/ml of water) (Luo et al. 2012). The pathogenicity tests were conducted using three replicates for each isolate (Ex 1, Ex 2 and Ex 3), two plants for each replicate and the inoculated plants were held in a greenhouse under ambient conditions $\left(20-25{ }^{\circ} \mathrm{C}, 75-85 \% \mathrm{RH}\right)$. Control plants were sprayed with sterile, distilled water. Plants were covered with plastic bags for $48 \mathrm{~h}$ to maintain high humidity. Inoculated plants were inspected for the disease symptom development daily for 10 days after inoculation. Leaf lesions were visible on all inoculated plants (18) after 3-4 days (Fig. 1b), but symptoms were not observed on control plants. The spots were red brown to brown and scattered over the whole leaf (Fig. 1b). The fungus was reisolated from leaf
Fig. 2 Exserohilum rostratum. a conidiophore. b-c conidia. Bar $=10 \mu \mathrm{m}$
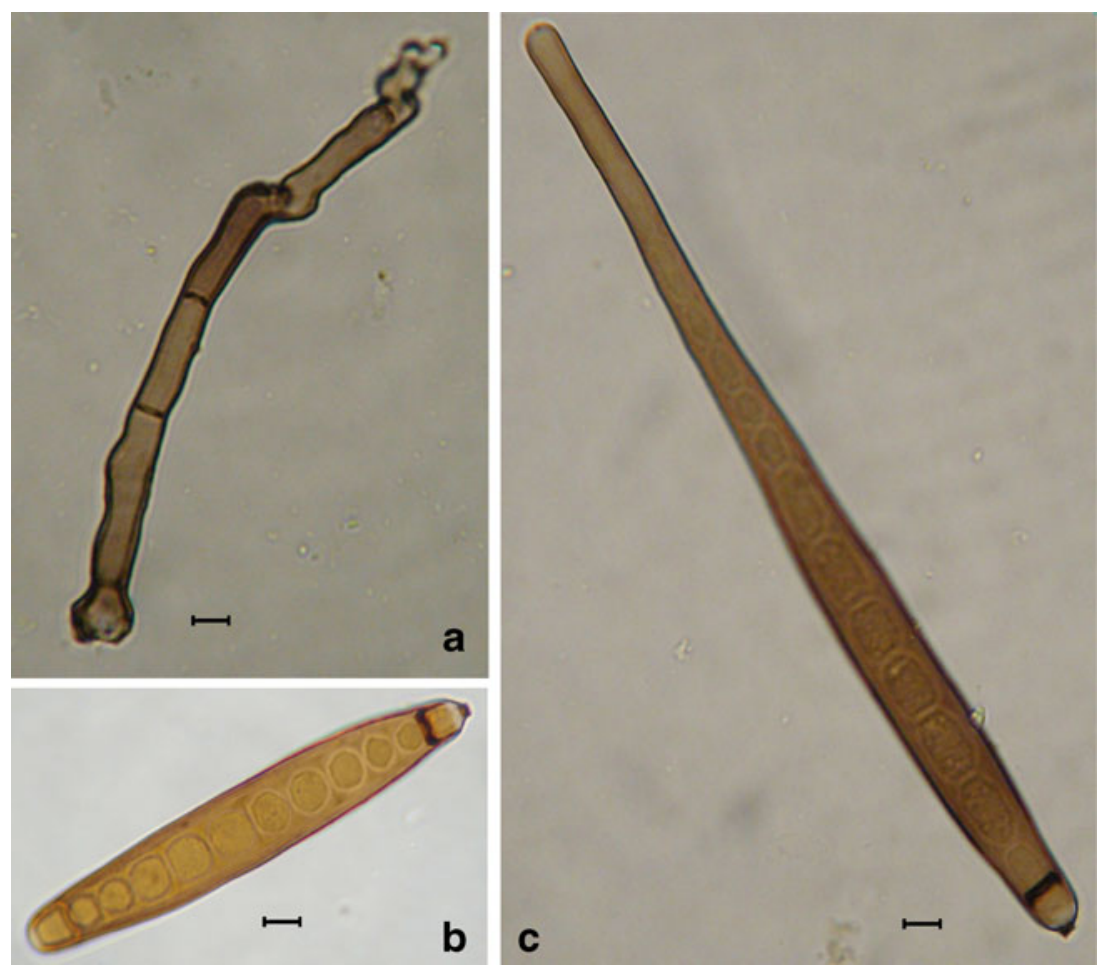
lesions on inoculated plants and morphologically identified, but not from leaves of control plants, confirming Koch's postulates.

Exserohilum rostratum has been reported previously on many monocotyledonous plants (Sivanesan 1987; Leonard et al. 1988; Cardona and González 2007; Luo et al. 2012), S. officinarum (Zummo 1986) and turfgrass species in Iran (Mirabolfathi and Ershad 2006). To our knowledge, this is the first report of leaf spot caused by E. rostratum on $S$. officinarum in Iran.

Acknowledgments The authors would like to thank of the University of Tehran for financial support.

\section{References}

Ahmadpour A, Heidarian Z, Donyadoost-Chelan M, Javan-Nikkhah M, Tsukiboshi T (2012) A new species of Bipolaris from Iran. Mycotaxon 120:301-307

Cardona R, González MS (2007) First report of Exserohilum rostratum associated with rice seed in Venezuela. Plant Dis 91:226
Leonard KJ, Thakur RP, Leath S (1988) Incidence of Bipolaris and Exserohilum species in corn leaves in North Carolina. Plant Dis 72:1034-1038

Liu D, Coloe S, Baird R, Pederson J (2000) Rapid mini-preparation of fungal DNA for PCR. J Clin Microbiol 38:471

Luo ZW, He F, Fan HY, Wang XH, Hua M, Hu FC, Li XH (2012) First report of leaf spot disease caused by Exserohilum rostratum on pineapple in Hainan province China. Plant Dis 96:458

Mirabolfathi M, Ershad D (2006) Bipolaris, Curvularia, Drechslera and Exserohilum diseases of turfgrass in Iran. Iran J Plant Pathol 42:257274

Okoli CAN, Erinle ID (1990) Comparative rate of rot-induction by nine fungal pathogens on stored tomato fruits in Nigeria. J Stored Prod Res 26:77-79

Revankar SG, Sutton DA (2010) Melanized fungi in human disease. Clin Microbiol Rev 23:884-928

Sivanesan A (1987) Graminicolous species of Bipolaris, Curvularia, Drechslera, Exserohilum and their teleomorphs. Mycological Papers No. 158, CAB International, Wallingford, UK

White TJ, Bruns T, Lee S, Taylor J (1990) Amplification and direct sequencing of fungal ribosomal RNA genes for phylogenetics. In: Innis MA, Gelfand DH, Sninsky JJ, White TJ (eds) PCR protocols: a guide to methods and applications'. Academic Press, San Diego, pp $315-322$

Zummo N (1986) Red spot (Helminthosporium rostratum) of sweet sorghum and sugarcane, a new disease resembling anthracnose and red rot. Plant Dis 70:800 